Brit. J. Ophthal. (1955), 39, 90.

\title{
KERATO-CONJUNCTIVITIS SICCA TREATED WITH CORTISONE AND ACTH*
}

BY

\author{
STELLA EADIE AND MALCOLM THOMPSON \\ Edinburgh
}

THE effects of cortisone and ACTH in cases of kerato-conjunctivitis sicca (KCS) have been recorded by several authors (Table I). Reports of their value have been conflicting, probably because most observers only treated a single case, and because in several instances only limited supplies of the hormones were available, so that treatment may have been inadequate.

TABLE I

RESULTS OF TREATMENT BY CORTISONE AND ACTH ALREADY RECORDED

\begin{tabular}{|c|c|c|c|c|}
\hline Authors & Date & $\begin{array}{l}\text { No. of } \\
\text { Cases }\end{array}$ & Treatment & Result \\
\hline $\begin{array}{l}\text { Offret and Forest } \\
\text { Phillips } \\
\text { Cristini } \\
\text { Beiglböck and Hoff } \\
\text { Fernández y Fernandes and } \\
\quad \text { Marañón } \\
\text { Forestier and others }\end{array}$ & $\begin{array}{l}1950,1951 \\
1952 \\
1952 \\
1952 \\
1952 \\
1951\end{array}$ & $\begin{array}{l}1 \\
1 \\
1 \\
1 \\
1 \\
1\end{array}$ & Cortisone & $\left.\begin{array}{l}\text { Unchanged } \\
\text { Unchanged } \\
\text { Improved } \\
\text { Improved } \\
\text { Improved } \\
\text { Improved }\end{array}\right\} 4$ \\
\hline $\begin{array}{l}\text { Cadman and Robertson } \\
\text { Cristini } \\
\text { Sjögren and Eriksen } \\
\text { Fitzgerald and others } \\
\text { Stephens } \\
\text { Forestier and others } \\
\text { Frenkel and others }\end{array}$ & $\begin{array}{l}1952 \\
1952 \\
1952 \\
1951 \\
1950 \\
1951 \\
1951\end{array}$ & $\begin{array}{l}2 \\
2 \\
4 \\
1 \\
1 \\
1 \\
1\end{array}$ & АCTH & $\left.\begin{array}{l}\text { Unchanged } \\
\text { Unchanged } \\
\text { Unchanged } \\
\text { Unchanged } \\
\text { Improved } \\
\text { Improved } \\
\text { Improved }\end{array}\right\} 3$ \\
\hline $\begin{array}{l}\text { Bourne } \\
\text { Phillips }\end{array}$ & $\begin{array}{l}1952 \\
1952\end{array}$ & $\begin{array}{l}1 \\
1\end{array}$ & $\begin{array}{l}\text { Cortisone } \\
\text { Eye Drops }\end{array}$ & $\underset{\text { Improved }}{\text { Improved }}\} 2$ \\
\hline
\end{tabular}

The purpose of this paper is to report on twelve cases of kerato-conjunctivitis sicca treated with cortisone drops, systemic cortisone, or ACTH. The cortisone drops used were a $\mathbf{0 . 6 2 5}$ per cent. solution of cortisone acetate (Merck) in a buffered base, except where stated otherwise.

* Received for publication August 20, 1954. 


\section{Case Notes}

Case 1, a female aged 41 years, had had rheumatic fever in childhood with resultant mitral stenosis and aortic regurgitation. She had had rheumatoid arthritis for 28 years, latterly associated with KCS, xerostoma, salivary gland enlargement, and a persistent dry cough with small areas of pulmonary atelectasis and recurrent laryngitis. The ocular symptoms were relieved during a course of oral cortisone in December, 1951.

An exacerbation of ocular symptoms occurred in October, 1952, when Schirmer's test gave $5 \mathrm{~mm}$. in both eyes, and vision was $6 / 60$ in the right eye, and 6/18 in the left. She was treated with cortisone drops three times daily and obtained relief within 48 hours. In November, 1952 , vision was $6 / 18$ in the right eye and 6/5 in the left. Staining was still present but less marked.

In March, 1953, a course of Acthar gel relieved her arthritic and ocular symptoms. The parotid and submandibular swellings subsided. Schirmer's test was not significantly improved (8 mm. maximum). A relapse occurred on cessation of ACTH therapy (April, 1953). The subsequent course is shown in Table II.

TABLE II

PROGRESS OF CASE 1

\begin{tabular}{|c|c|c|c|c|c|c|c|c|}
\hline \multirow{2}{*}{$\begin{array}{l}\text { Date of } \\
\text { Exam- } \\
\text { ination }\end{array}$} & \multicolumn{4}{|c|}{ Right Eye } & \multicolumn{4}{|c|}{ Left Eye } \\
\hline & Symptoms & Staining & Vision & $\begin{array}{l}\text { Schirmer's } \\
\text { Test (mm.) }\end{array}$ & Symptoms & Staining & Vision & $\begin{array}{l}\text { Schirmer's } \\
\text { Test (mm.) }\end{array}$ \\
\hline \multirow[t]{2}{*}{$\overline{13.11 .53}$} & +++ & +++ & $6 / 36$ & 2 & +++ & +++ & $6 / 36$ & 2 \\
\hline & \multicolumn{4}{|c|}{ No treatment } & \multicolumn{4}{|c|}{ No treatment } \\
\hline \multirow[t]{2}{*}{$\overline{20.11 .53}$} & +++ & +++ & $6 / 36$ & $\mathbf{0}$ & +++ & +++ & $6 / 24 \mathrm{pt}$ & 3 \\
\hline & \multicolumn{4}{|c|}{ Cortisone drops 3-hrly } & \multicolumn{4}{|c|}{ Cortisone drops 3-hrly } \\
\hline \multirow[t]{2}{*}{27.11 .53} & ++ & +++ & $6 / 12$ & 2 & + & ++ & $6 / 18+$ & 4 \\
\hline & \multicolumn{4}{|c|}{ Cortisone drops three times daily } & \multicolumn{4}{|c|}{ Cortisone drops three times daily } \\
\hline \multirow[t]{2}{*}{11.12 .53} & ++ & +++ & $6 / 24$ & 0 & ++ & ++ & $6 / 18+$ & 0 \\
\hline & \multicolumn{4}{|c|}{ Cortisone drops three times daily } & \multicolumn{4}{|c|}{ Cortisone drops three times daily } \\
\hline \multirow[t]{2}{*}{23.12 .53} & ++ & +++ & $6 / 18+$ & 4 & + & ++ & $6 / 9$ & 3 \\
\hline & \multicolumn{4}{|c|}{ Hydrocortisone drops three times daily } & \multicolumn{4}{|c|}{ Cortisone drops three times daily } \\
\hline \multirow[t]{2}{*}{8.1 .54} & 0 & ++ & $6 / 12$ & 0 & 0 & +++ & $6 / 12 \mathrm{pt}$. & 3 \\
\hline & \multicolumn{4}{|c|}{ Hydrocortisone drops three times daily } & \multicolumn{4}{|c|}{ Cortisone drops three times daily } \\
\hline \multirow[t]{2}{*}{22.1 .54} & 0 & ++ & $6 / 9 \mathrm{pt}$ & 0 & 0 & +++ & $6 / 18+$ & 3 \\
\hline & \multicolumn{4}{|c|}{ Hydrocortisone drops three times daily } & \multicolumn{4}{|c|}{ Cortisone drops three times daily } \\
\hline \multirow[t]{2}{*}{ 14.2.54 } & 0 & ++ & $6 / 9+$ & 一 & 0 & ++ & $6 / 9$ & - \\
\hline & \multicolumn{4}{|c|}{ Hydrocortisone drops three times daily } & \multicolumn{4}{|c|}{ Cortisone drops three times daily } \\
\hline \multirow[t]{2}{*}{26.2 .54} & + & +++ & 6/9pt. & 2 & + & +++ & 6/9pt. & 3 \\
\hline & \multicolumn{4}{|c|}{ Lacrimal puncta sealed } & \multicolumn{4}{|l|}{ Nil } \\
\hline 31.5 .54 & 0 & ++ & $6 / 6+$ & 5 & ++ & +++ & $6 / 24$ & 5 \\
\hline
\end{tabular}


Case 2, a female aged 64 years, had had severe rheumatoid arthritis for 25 years, and intermittent soreness of the eyes for 8 years. Schirmer's test gave $3 \mathrm{~mm}$. in both eyes. In March, 1953, vision was $6 / 18$ in the right eye and 6/60 in the left. She was treated with cortisone drops three times daily, and in April, 1953, vision was 6/6 in the right eye and 6/36 in the left. When treatment was discontinued in July, 1953, she relapsed, but she improved again when treatment was resumed. In November, 1953, while she was still receiving drops, vision was $6 / 5$ in the right eye and $6 / 9$ in the left. Schirmer's test showed $4 \mathrm{~mm}$. in both eyes. The cortisone drops were then withdrawn. The subsequent course is shown in Table III.

TABLE III

PROGRESS OF CASE 2

\begin{tabular}{|c|c|c|c|c|c|c|c|c|}
\hline \multirow{2}{*}{$\begin{array}{c}\text { Date of } \\
\text { Exam- } \\
\text { ination }\end{array}$} & \multicolumn{4}{|c|}{ Right Eye } & \multicolumn{4}{|c|}{ Left Eye } \\
\hline & Symptoms & Staining & Vision & \begin{tabular}{|l|} 
Schirmer's \\
Test $(\mathrm{mm})$.
\end{tabular} & Symptoms & Staining & Vision & $\begin{array}{l}\text { Schirmer's } \\
\text { Test }(\mathrm{mm} \text {.) }\end{array}$ \\
\hline \multirow[t]{2}{*}{10.12 .53} & $++t$ & - & $6 / 5$ & 5 & $+t+$ & - & $6 / 12$ & 4 \\
\hline & \multicolumn{4}{|c|}{ Cortisone drops three times daily } & \multicolumn{4}{|c|}{ Cortisone drops three times daily } \\
\hline \multirow[t]{2}{*}{15.12 .53} & + & $+t+$ & 6/6pt. & - & + & $+t+$ & $6 / 12+$ & - \\
\hline & \multicolumn{4}{|l|}{ Nil } & \multicolumn{4}{|l|}{ Nil } \\
\hline \multirow[t]{2}{*}{18.1 .54} & + & $++t$ & 6/6pt. & 10 & + & $t+t$ & $6 / 12+$ & 10 \\
\hline & \multicolumn{4}{|l|}{$\mathrm{Nil}$} & \multicolumn{4}{|l|}{ Nil } \\
\hline \multirow[t]{2}{*}{9.2 .54} & + & $+t+$ & 6/6pt. & 6 & $t+t$ & $t+t$ & $6 / 60$ & 3 \\
\hline & \multicolumn{4}{|l|}{ Nil } & \multicolumn{4}{|c|}{ Cortisone drops four times daily } \\
\hline \multirow[t]{2}{*}{19.2 .54} & + & +++ & 6/5pt. & 4 & + & +++ & $6 / 18$ & 8 \\
\hline & \multicolumn{4}{|l|}{ Nil } & \multicolumn{4}{|c|}{ Cortisone drops four times daily } \\
\hline \multirow[t]{2}{*}{25.3 .54} & + & ++ & $6 / 6$ & - & + & +++ & $6 / 18+$ & 一 \\
\hline & \multicolumn{4}{|l|}{ Nil } & \multicolumn{4}{|c|}{ Hydrocortisone drops four times daily } \\
\hline \multirow[t]{2}{*}{6.5 .54} & + & +++ & 6/6pt. & 0 & + & +++ & $6 / 36$ & 1 \\
\hline & \multicolumn{4}{|l|}{ Nil } & \multicolumn{4}{|c|}{ Lacrimal puncta sealed } \\
\hline \multirow[t]{2}{*}{21.5 .54} & ++ & +++ & 6/6pt. & 1 & 0 & ++ & $6 / 9$ & 4 \\
\hline & \multicolumn{4}{|c|}{ Cortisone drops three times daily } & \multicolumn{4}{|c|}{ Puncta still sealed } \\
\hline 17.6.54 & 0 & 一 & 6/5pt. & - & 0 & - & 6/6pt. & - \\
\hline
\end{tabular}

Case 3, a female aged 47 years, had had xerostoma and inflamed eyes for 5 years, with no rheumatoid arthritis, but anaemia and achlorhydria. She obtained no relief from large doses of vitamins and oral iron, nor from antibiotic eye drops. In June, 1953, she had severe KCS; vision was $6 / 18$ in the right eye and $6 / 9+$ in the left. Treatment with cortisone drops three times a day gave symptomatic relief and the corneal staining decreased. Cortisone drops were discontinued in November, 1953. The subsequent course is shown in Table IV (opposite). 
TABLE IV

PROGRESS OF CASE 3

\begin{tabular}{|c|c|c|c|c|c|c|c|c|}
\hline \multirow{2}{*}{$\begin{array}{l}\text { Date of } \\
\text { Exam- } \\
\text { ination }\end{array}$} & \multicolumn{4}{|c|}{ Right Eye } & \multicolumn{4}{|c|}{ Left Eye } \\
\hline & Symptoms & Staining & Vision & $\begin{array}{l}\text { Schirmer's } \\
\text { Test (mm.) }\end{array}$ & Symptoms & Staining & Vision & $\begin{array}{l}\text { Schirmer's } \\
\text { Test (mm.) }\end{array}$ \\
\hline \multirow[t]{2}{*}{5.11 .53} & +++ & +++ & $6 / 18$ & 2 & +++ & +++ & $6 / 9$ & 6 \\
\hline & \multicolumn{4}{|l|}{ Nil } & \multicolumn{4}{|l|}{ Nil } \\
\hline \multirow[t]{2}{*}{10.11 .53} & +++ & +++ & 6/18pt. & 0 & +++ & +++ & 6/9pt. & 0 \\
\hline & \multicolumn{4}{|c|}{ Intensive vitamin therapy } & \multicolumn{4}{|c|}{ Intensive vitamin therapy } \\
\hline \multirow[t]{2}{*}{5.1 .54} & +++ & +++ & 6/24pt. & 2 & +++ & +++ & 6/9pt. & 0 \\
\hline & \multicolumn{4}{|c|}{$\begin{array}{l}\text { Cortisone drops } 3 \text {-hrly for } 2 \text { days then } \\
\text { four times daily }\end{array}$} & \multicolumn{4}{|c|}{$\begin{array}{l}\text { Cortisone drops } 3 \text {-hrly for } 2 \text { days then } \\
\text { four times daily }\end{array}$} \\
\hline \multirow[t]{2}{*}{ 19.1.54 } & ++ & +++ & 6/18pt. & $\mathbf{0}$ & + & ++ & 6/9pt. & $\mathbf{0}$ \\
\hline & \multicolumn{4}{|c|}{ Cortisone drops four times daily } & \multicolumn{4}{|c|}{ Cortisone drops four times daily } \\
\hline \multirow[t]{2}{*}{2.2 .54} & ++ & +++ & $6 / 24 p t$ & $\mathbf{0}$ & + & +++ & $6 / 12$ & 0 \\
\hline & \multicolumn{4}{|c|}{ Lacrimal puncta sealed } & \multicolumn{4}{|c|}{ Cortisone drops four times daily } \\
\hline \multirow[t]{2}{*}{ 16.2.54 } & + & +++ & $6 / 18+$ & 6 & + & ++ & $6 / 12+$ & 0 \\
\hline & \multicolumn{4}{|c|}{ Lacrimal puncta sealed } & \multicolumn{4}{|c|}{ Cortisone drops four times daily } \\
\hline \multirow[t]{2}{*}{ 26.2.54 } & + & ++ & 6/12pt. & 2 & + & +++ & $6 / 12+$ & $\mathbf{0}$ \\
\hline & \multicolumn{4}{|c|}{ Lacrimal puncta re-sealed } & \multicolumn{4}{|c|}{ Lacrimal puncta sealed } \\
\hline \multirow[t]{2}{*}{ 13.3.54 } & $\mathbf{0}$ & 一 & - & 4 & $\mathbf{0}$ & - & - & 6 \\
\hline & \multicolumn{4}{|c|}{ Lacrimal puncta still sealed } & \multicolumn{4}{|c|}{ Lacrimal puncta still sealed } \\
\hline 4.5 .54 & + & + & $6 / 12 \mathrm{pt}$ & 6 & $\mathbf{0}$ & ++ & $6 / 9 \mathrm{pt}$ & 6 \\
\hline
\end{tabular}

Case 4, female aged 54 years, had had severe rheumatoid arthritis for 25 years, sore eyes intermittently for 18 months, xerostoma, and bilateral parotid swelling. In December, 1953, the right eye was enucleated after perforation of a corneal ulcer. The left eye showed KCS, Schirmer's test gave $4 \mathrm{~mm}$., and vision in the left eye was 6/12. Cortisone drops three times a day gave only slight subjective improvement. The staining and Schirmer's test did not improve and vision in the left eye deteriorated to $6 / 18$. Cortisone was instilled 5 times daily without further improvement. In February, 1954, the left lacrimal puncta and canaliculi were sealed, giving marked symptomatic improvement. In May, 1954, the improvement was maintained, vision was 6/6, and Schirmer's test gave $3 \mathrm{~mm}$., but the corneal staining was still present.

Case 5, female aged 44 years, had had rheumatoid arthritis for 22 years, recurrent laryngitis, and inflamed eyes for one year. Various eye drops had not given any relief. In February, 1954, vision was 6/18 in both eyes, KCS was present, and Schirmer's test gave $3 \mathrm{~mm}$. in the right eye and $1 \mathrm{~mm}$. in the left. Cortisone drops 1.5 per cent. solution were given four times a day to the right eye and hydrocortisone drops 1.5 per cent. solution four times a day to the left eye. After 2 weeks the symptoms in the right eye were relieved, but no improvement was seen in the left eye. Vision was $6 / 9$ in the right eye 
and 6/24 in the left eye. Later cortisone drops 1.5 per cent. solution were given four times daily to both eyes, but there was no change in the condition of the left eye.

Treatment was discontinued in April, 1954, and a full relapse occurred. In May, 1954, cortisone drops four times daily were combined with cortisone ointment applied to the eyes at night. After 2 weeks, the right eye had again responded but there was no improvement in the left eye. In June, 1954, the left lacrimal puncta were sealed and cortisone to the left eye was stopped. The eye improved with complete symptomatic relief and vision improved to 6/9. This improvement has been maintained.

Case 6, a female aged 38 years, had had rheumatoid arthritis for 17 years, with Raynaud's disease, xerostoma, intermittent bilateral parotid swellings, recurrent laryngitis, and attacks of "conjunctivitis". In November, 1954, she was thought to have KCS; Schirmer's test gave $0 \mathrm{~mm}$. in the right eye and $1 \mathrm{~mm}$. in the left eye. Vision was $6 / 9$ in both eyes. Cortisone drops were given four times daily with marked subjective relief in both eyes and reduction of staining in the right. The cortisone was reduced to three times daily and the improvement was maintained. In January, 1954, 1 per cent. hydrocortisone drops were given four times daily to the left eye and cortisone 1 per cent. four times daily to right eye. There was no further improvement in either eye.

Case 7, a female aged 46 years, had had alopecia totalis since 1940, dry skin and trophic changes in the nails since 1946, xerostoma and dry cough since 1948, recurrently sore eyes since April, 1951, and severe sinusitis and rheumatoid arthritis since September, 1951. In February, 1952, she was given oral cortisone $100 \mathrm{mg}$. daily, with relief of ophthalmic symptoms and improvement in general condition. Schirmer's test gave $8 \mathrm{~mm}$. in both eyes. The visual acuity was $6 / 6$ in each eye. After one year of therapy, Schirmer's test gave $2 \mathrm{~mm}$. in the right eye and $3 \mathrm{~mm}$. in the left eye. Staining with rose bengal solution was present throughout.

After 2 years of treatment, oral cortisone therapy was withdrawn during January, 1954, and the ocular symptoms recurred within a few days of withdrawal, with bilateral conjunctival injection. Cortisone eye-drops were given, and it was necessary to instil the drops 2-hourly to relieve the patient's symptoms completely. Schirmer's test continued to give $2 \mathrm{~mm}$. in both eyes.

Oral cortisone therapy, $75 \mathrm{mg}$. daily, was resumed in February, and this partially controlled the ocular and arthritic symptoms; when the dosage was increased to $100 \mathrm{mg}$. daily, the symptoms were completely relieved.

Case 8, a female aged 66 years, had had severe rheumatoid arthritis for 4 years, and xerostoma and KCS for 1 year. In July, 1952, she was treated with cortisone eye-drops three times daily and chloramphemical eye ointment at night. Relief was obtained but the patient relapsed when the cortisone was stopped. In October, 1952, cortisone eyedrops were given to the left eye three times daily with marked symptomatic improvement.

Case 9, female aged 59 years, had had rheumatoid arthritis for 13 years, recurrent attacks of conjunctival injection for 3 years, and xerostoma. In January, 1954, examination revealed Sjögren's syndrome with signs of Felty's syndrome.

When mild exacerbation of ocular symptoms occurred in February, 1954, Schirmer's test gave $3 \mathrm{~mm}$. in both eyes, and 1 per cent. cortisone eye-drops four times daily gave relief within 3 days; after 9 days of treatment the drops were withdrawn and relapse occurred. Further therapy with 1 per cent. cortisone eye-drops four times daily was then given for 3 weeks with prompt relief; since the end of course the patient has had no further ocular symptoms.

Case 10, a female aged 60 years, had had severe rheumatoid arthritis for 20 years, and sore eyes and photophobia for 1 year, with xerostoma; KCS was diagnosed and Schirmer's test gave $3 \mathrm{~mm}$. in the right eye and $5 \mathrm{~mm}$. in the left; vision was $6 / 24$ in the right eye and $6 / 9$ in the left. 
The ocular symptoms had not been relieved by various eye-drops, but improved after subconjunctival injections of $0 \cdot 3-\mathrm{ml}$. $2 \frac{1}{2}$ per cent. cortisone acetate solution.

In April, 1954, oral cortisone $50 \mathrm{mg}$. daily caused some relief of the arthritis, but there was an exacerbation of the ocular symptoms which was controlled by cortisone drops. The response to Schirmer's test remained unaltered.

Case 11, a female aged 53 years, had had rheumatoid arthritis for 12 years, and recurrent ocular inflammation and corneal ulceration for 9 years. In May, 1954, KCS was diagnosed and Schirmer's test gave $2 \mathrm{~mm}$. in the right eye and $11 \mathrm{~mm}$. in the left. Vision was $6 / 5$ in the right eye and 6/6 in the left. Corneal scarring was seen in the left eye. Treatment was begun with hydrocortisone eye-drops 0.625 per cent. four times daily to the left eye and cortisone eye-drops four times daily to the right eye. After 2 weeks, subjective improvement occurred in both eyes, but the ophthalmic appearance were unchanged. Schirmer's test gave zero results in both eyes.

Case 12, a female aged 53 years, had had rheumatoid arthritis for 18 years, and recurrent sore eyes and xerostoma for 6 months. In November, 1953, KCS was diagnosed and Schirmer's test gave $8 \mathrm{~mm}$. in the right eye and $4 \mathrm{~mm}$. in the left. Vision was $6 / 6$ part in both eyes. Cortisone drops were given 3-hourly for 2 days, and then three times daily in both eyes; after 1 week there was considerably subjective improvement, but the vision was unaltered and Schirmer's test still gave $2 \mathrm{~mm}$. in the right eye and $1 \mathrm{~mm}$. in the left.

\section{Results of Treatment}

(a) Topical Therapy.-Cortisone eye-drops were used in the treatment of twelve patients, of whom eight obtained definite and marked relief of symptoms, three obtained partial relief when the drops were instilled frequently, and one derived no benefit. When cortisone eye-drops were effective, the benefit was usually definite within 4 days of starting treatment. Cessation of therapy usually resulted in prompt relapse, but in two instances (Cases 2 and 9) the patients enjoyed relatively prolonged remissions after cortisone was withdrawn.

Hydrocortisone eye-drops were administered to five patients. In only one instance did the benefit obtained from hydrocortisone significantly exceed that derived from cortisone (Case 1). One patient found both local cortisone and hydrocortisone equally ineffective.

The addition of cortisone eye ointment to local therapy in two cases gave no extra benefit.

(b) Systemic Therapy.-Oral cortisone therapy was given to three patients. In two instances (Cases 1 and 7) it was effective in controlling symptoms, but in one (Case 10) $50 \mathrm{mg}$. daily did not control the ocular symptoms. One patient (Case 1) also had a course of ACTH with suppression of ocular symptoms. Systemic cortisone and ACTH did not lead to any significant increase in lacrimal secretion.

(c) Sealing Lacrimal Puncta and Canaliculi.-This operation was carried out in five patients, all of whom obtained very marked relief, including one who had completely failed to improve (Case 4) and two patients (Cases 3 and 5) who had improved only slightly with cortisone eye-drops. 


\section{Discussion}

It has been possible to evaluate critically the results of treatment with local cortisone. Contrel of observations was possible by observing the response in one eye treated with local cortisone while the other eye remained untreated; and also by using interrupted courses of treatment.

The response to local cortisone therapy $(0.625$ per cent. solution three times daily) was generally good. For the more severe cases stronger preparations were found to be more effective, and more frequent instillation was required. Hydrocortisone eye-drops did not appear to be any more effective than cortisone, although hydrocortisone is usually considered to be more active locally. The addition of cortisone eye ointment to local therapy did not augment the therapeutic response.

Cortisone and hydrocortisone are presumably effective in local treatment by virtue of their direct anti-inflammatory action on the corneal and conjunctival tissues. Amelioration of symptoms and improvement of vision corresponded with reduction of vascular hyperæmia and mucoid exudate. There was usually a definite decrease in the corneal filaments and staining reaction, but this latter finding was not invariably the rule. Topical therapy did not lead to any increased lacrimal secretion as measured by Schirmer's test.

Five patients, three of whom had obtained only slight benefit from the use of cortisone, all received marked benefit from the sealing of the lacrimal puncta. Increase in the values given by Schirmer's test was sometimes noted, but was not so striking as in the cases recorded by Holm (1949). It is considered that although sealing the lacrimal puncta is the most effective treatment of severe kerato-conjunctivitis sicca, it may give rise to troublesome epiphora and should therefore be reserved for the more severe or persistent cases who either show an inadequate response to local cortisone therapy or who require prolonged treatment.

\section{Summary}

Twelve cases of kerato-conjunctivitis sicca are described. Cortisone eye-drops satisfactorily relieved symptoms in most cases. Hydrocortisone drops did not appear to be more effective, nor did the addition of cortisone eye ointment confer any extra benefit. Systemic cortisone and ACTH therapy were effective, but their use is not warranted in the treatment of this condition.

Sealing the lacrimal canaliculi relieved the more severe cases, and this form of treatment is most valuable in patients who require prolonged topical cortisone or whose response is inadequate.

We gratefully acknowledge the invaluable advice and co-operation of Dr. G.-I. Scott of Edinburgh Royal Infirmary, and Dr. J. J. R. Duthie of the Northern General Hospital, Edinburgh. During the period when this work was undertaken, the Rheumatic Unit, Northern General 
Hospital, was in receipt of grants from the Nuffield Foundation and Medical Research Council, and one of us (S. E.) received a grant from the W. H. Ross Foundation (Scotland) for the Prevention of Blindness.

The cortisone and ACTH used in the treatment of several of these patients was supplied by the Medical Research Council, to whom we are indebted.

\section{REFERENCES}

Beiglböck, W., and Hoff, H. (1952). Dtsch. med. Wschr., 77, 7, 42.

BOURNe, L. B. (1952). Brit. med. J., 2, 446.

CAdMAN, E. F. B., and RobertSon, A. J. (1952). Ibid., 2, 68.

CRISTINI, G. (1952). Riv. Oto-neuro-oftal., 27, 59.

DUKe-Elder, S. (1951). British Journal of Ophthalmology, 35, 666.

Fernández y Fernandes, M., and Maranón, G. (1952). Bol. Inst. Patol. méd. (Madr.), 7, 6 Abs. in Ophthal. Lit. (Lond.) (1953). 6, p. 528, No. 2636.

Fitzgerald, J. R., Bellows, J. G., Donegan, J. M., Gamble, R. C., Krause, A. C., ManN, W. A., Pearlman, M. D., and Zekman, J. N. (1951). Arch. Ophthal. (Chicago), 45, 320.

Forestier, J., Certonciny, A., Jacqueline, F., and Saint-MarC, J. (1951). Rev. Rhum., 18, 167.

Frenkel, M., Hellinga, G., and Groen, J. (1951). Acta. endocrinol. (Kbh.), 6, 161.

Holm, S. (1949). Acta ophthal. (Kbh.), Suppl. 33.

OfFret, G., and Forest, ?. (1950). Bull. Soc. Ophtal. France., No. 9, p. 759

- (1951). Ibid., No. 1, p. 20. Quoted by Duke-Elder (1951).

Phillips, C. (1952). Arch. Ophthal. (Chicago), 48, 518.

SJögren, H., and ERIKSEN, A. (1952). Acta ophthal. (Kbh.), 30, 463.

StePhens, C. A. L. (1950). "Proceedings First Clinical ACTH Conference”, ed. J. R. Mote, p. 358. Churchill, London. 